\title{
Investigation of the factors influencing the interfacial heat transfer coefficient in
}

\section{hot stamping}

Ying Chang a , Xinghui Tang a, Kunmin Zhao ${ }^{\text {a, }}$, Ping $\mathrm{Hu}^{\text {a }}$, Yucheng Wu ${ }^{\mathrm{b}}$

a Dalian University of Technology, School of Automotive Engineering, State Key Lab of Structural Analysis for Industrial Equipment, Dalian 116024, China

${ }^{\mathrm{b}}$ Hefei University of Technology, Heduan Research Institute, Hefei 230601, China

* Corresponding author. E-mail: kmzhao@dlut.edu.cn Phone: +8641184706475

Postal Address: LingGong Road, Dalian, 116024, China

\begin{abstract}
In hot stamping of advanced high strength steel (AHSS) parts, the interfacial heat transfer coefficient (IHTC) between part and die has a direct impact on the temperature distribution in the part and consequently affects the microstructure and mechanical properties of the part. In this paper, a cylindrical-die experimental model was designed, experiments on boron steel 22MnB5 were conducted, the Beck's non-linear estimation method was used to calculate the IHTC, and the factors that influence IHTC were investigated. First, the influence of surface topography was studied. Both contact pressure and blank surface roughness impact the topography at the interface between die and blank. The interfacial topography determines the actual contacting area, which impacts the interfacial heat flow resistance and consequently the value of IHTC. The IHTC correlates highly with contact pressure by a positive power function. It also increases significantly with decreasing surface roughness but slows down when the roughness is less than $1 \mu \mathrm{m}$ and saturates at high contact pressure. Second, the influence of material thermo-physical properties was analyzed. The IHTC between 22MnB5 blank and \#45-tool-steel die is approximately twice as much as that of H13-tool-steel die. The martensitic transformation yields a positive gain on IHTC by approximately $30 \%$. The combination of phase transformation induced thermal conductivity increasing and latent heat
\end{abstract}


releasing results in a sharp increase of the IHTC near the $M_{s}$ point. Third, the influence of anti-oxidation surface coating was evaluated. Although the oxidation preventive oil coating can reduce oxidation of the blank to a certain degree, it weakens the heat transfer performance. The IHTC decreases more with a thicker coating.

Keywords: Hot stamping, Interfacial heat transfer coefficient (IHTC), Beck's estimation method, Martensitic transformation, Advanced high strength steel (AHSS)

\section{Introduction}

The hot stamping process is defined as the boron steel sheets such as $22 \mathrm{MnB} 5$ are heated to over $900^{\circ} \mathrm{C}$ for completely uniform austenitizing and then transferred to water-cooling dies for stamping and quenching at cooling rates of over $27^{\circ} \mathrm{C} / \mathrm{s}$. Turetta et al. (2006) investigated the formability of 22MnB5 in hot stamping operations. Karbasian and Tekkaya (2010) further reviewed the thermal, mechanical, microstructural, and technological fields of this forming process. Hot stamped high-strength steel parts have the advantages of high strength, high hardness, little springback and significant weight reduction, all of which make hot stamping the best process for producing complex automotive structural components such as A-pillars, B-pillars and side impact beams etc.

During forming and quenching of the hot stamping process, heat transfers between high-temperature blank and low-temperature die. The interfacial heat transfer coefficient (IHTC) between blank and die is an important thermophysical parameter indicating heat transferability. The IHTC directly impacts the temperature distribution in the blank and consequently affects the mechanical property and microstructure of the formed part. The IHTC is needed in numerical simulation (finite element analysis etc) of heat transfer problems and the accurate IHTC is necessary for reliable simulation results.

In heat transfer theory, the IHTC is a parameter to describe the heat transfer between interfaces and considered as a constant value in ideal condition (Yang and Tao, 2006). However, an ideal 
condition is difficult to achieve in practice and the IHTC is influenced by many complicated factors. Ikeuchi and Yanagimoto (2011) has demonstrated that the contact load, the temperature of blank and die, the surface roughness and the thermophysical properties of the material all influence the IHTC. Merklein et al. (2009) investigated the IHTC for given contact pressure and temperature difference through experiments, and compared the gap heat transfer coefficients (GHTC) for various gap values. Abdulhay et al. (2012) obtained the thermal contact resistance at different locations of a U-shape part with estimated contact pressure from $2 \mathrm{MPa}$ to $30 \mathrm{MPa}$, and approximated an exponential function relationship between the thermal contact resistance and the contact pressure. Shojaefard and Goudarzi (2008) studied the heat transfer between stainless steel and aluminum based steady-state experiments. Blaise et al. (2013) analyzed the changes of thermal contact resistance of Usibor 1500P steel during hot stamping. Recent years have seen increasing applications of boron steel in hot stamping and emerging studies of the factors that influence the IHTC during forming and subsequent quenching. For example, Hu et al. (2013) studied the effect of oxide scale on IHTC for a typical type of boron steel 22MnB5. There are few investigations, though, on other influencing factors for this material.

There are two relatively mature methods for calculating the ITHC. One method is to treat the problem as inverse heat conduction problem illustrated by Bai et al. (2012), i.e. inversely solve the heat flux and temperature at the interface from the measured temperature fields of the blank and die, given IHTC as boundary conditions, and the optimal IHTC values are obtained by minimizing the difference between the calculated and measured temperatures of the blank and die. The other method is to simulate the temperature field by using finite element model and determine the optimal IHTC value through an iteration process. This method only provides a single equivalent IHTC, which cannot reflect the actual changes of the IHTC during the forming and quenching process. Therefore, the second method is less accurate than the first one.

In this paper, a heat transfer device was designed and an optimization program based on Beck's 
non-linear estimation method was developed (Beck et al. 1985). The optimal IHTC values were calculated and the influencing factors on IHTC were investigated. The factors include the microstructure at the interface between die and blank, the thermophysical parameters of die and blank, and the anti-oxidation coating on the blank.

\section{Experiment Description and Calculation of IHTC}

\subsection{Experiment device and temperature acquisition}

The experiment setup illustrated in Fig. 1 consists of a 40-ton hydraulic press, an electric furnace, a two-piece cylindrical die (upper and lower), a circular 22MnB5 steel blank of $2.0 \mathrm{~mm}$ thickness, five thermocouples, a data acquisition device MX100 and a desktop computer. The spherical contact in the support helps balance the lower die and ensure an uniform contact pressure on the blank. Fig. 2 shows the dimensions of the die and blank, and the temperature collecting positions. One thermocouple is fusion welded onto the surface of the upper die and smoothed flat. The temperature collected by this thermocouple is considered the temperature on the die surface. Three thermocouples are installed in the lower die at $2 \mathrm{~mm}, 4 \mathrm{~mm}, 6 \mathrm{~mm}$ below the die surface, respectively. One thermocouple is installed right in the middle of the blank.

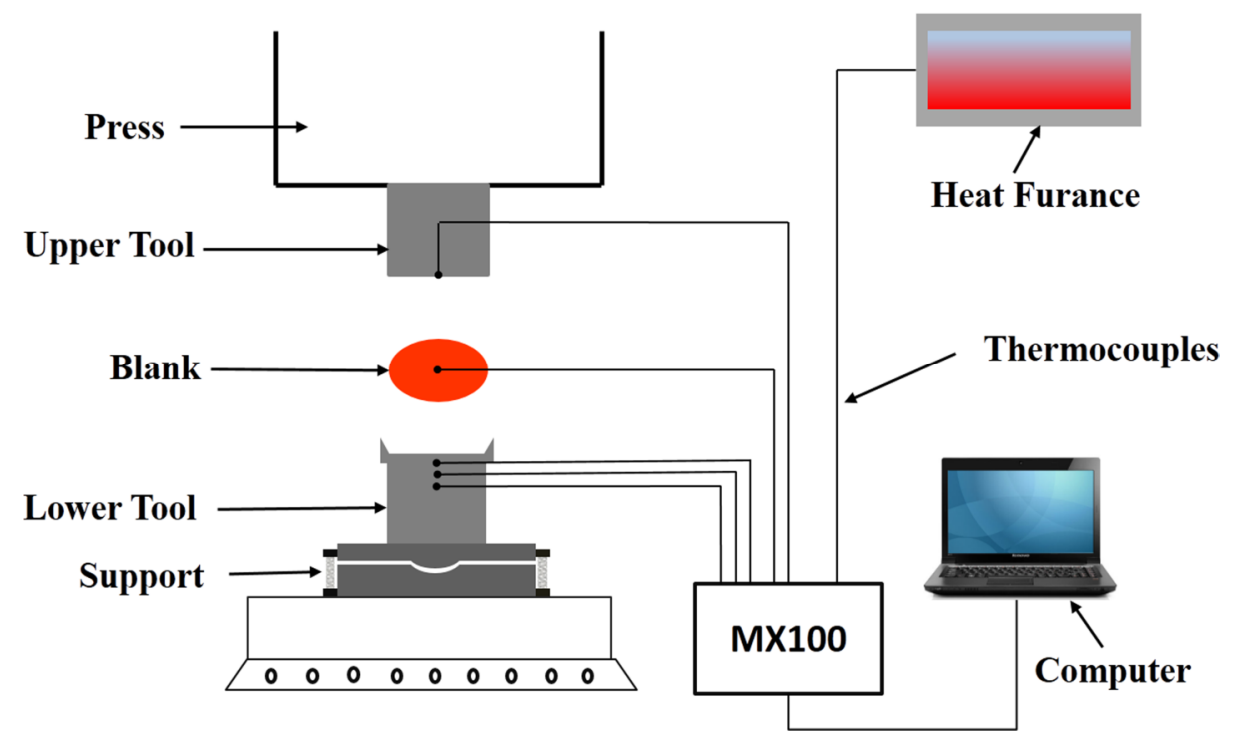

Fig. 1. Schematic illustration of the experiment setup 


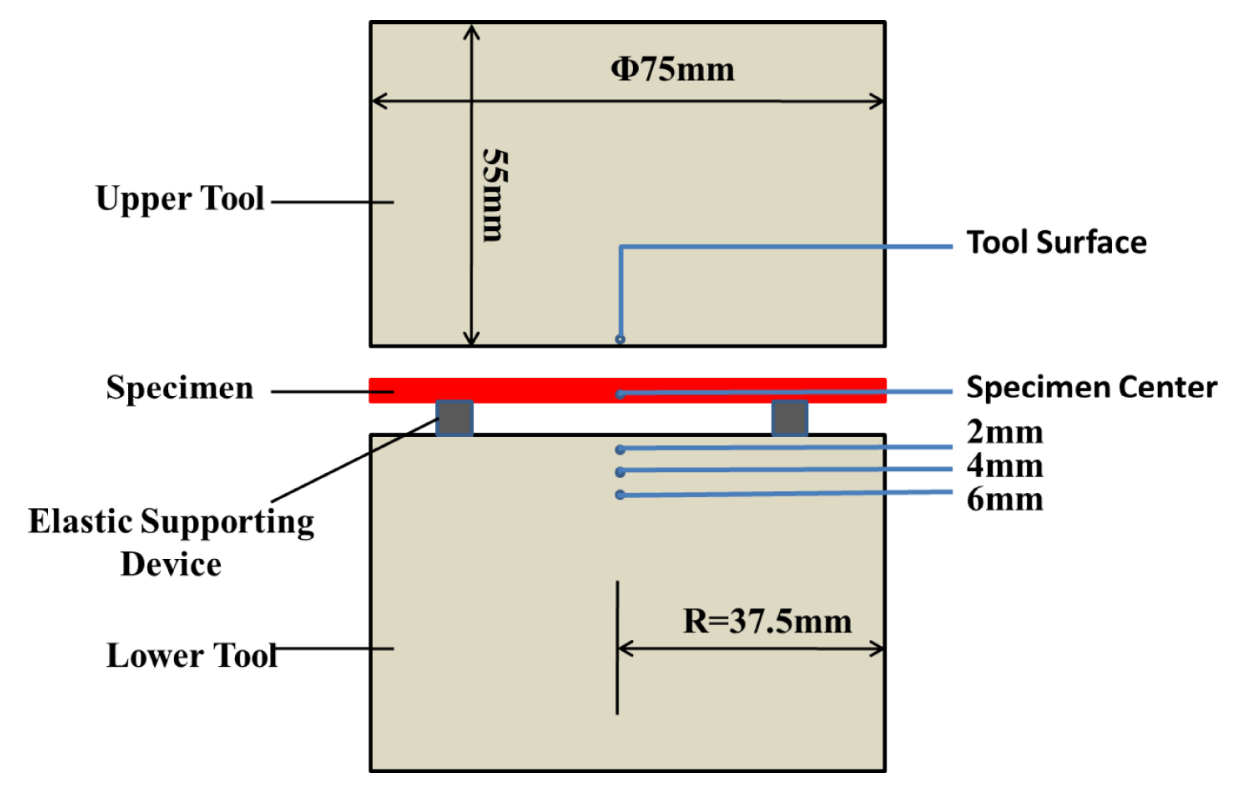

Fig. 2. Dimensions of the heat transfer device and the thermocouple positions

In the experiment, the blank was heated in the furnace to $900^{\circ} \mathrm{C}$ and kept for 3 minutes, then quickly transferred onto the lower die. The upper die slid down and pressed the blank against the lower die at a certain pressure. Fig. 3 shows the heated specimen and thermocouple wiring. The measured temperatures of the blank and the \#45 tool steel die for 1.0 MPa contact pressure are plotted in Fig. 4.

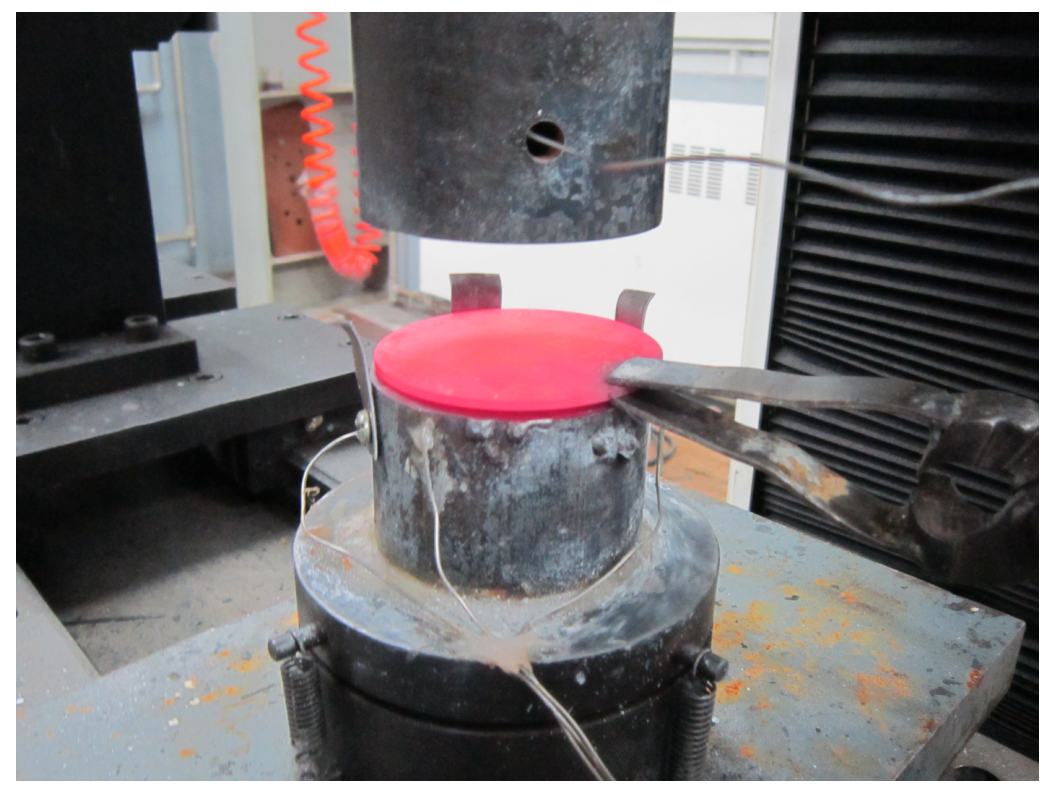

Fig. 3. Experiment setup showing the specimen and thermocouple wiring 


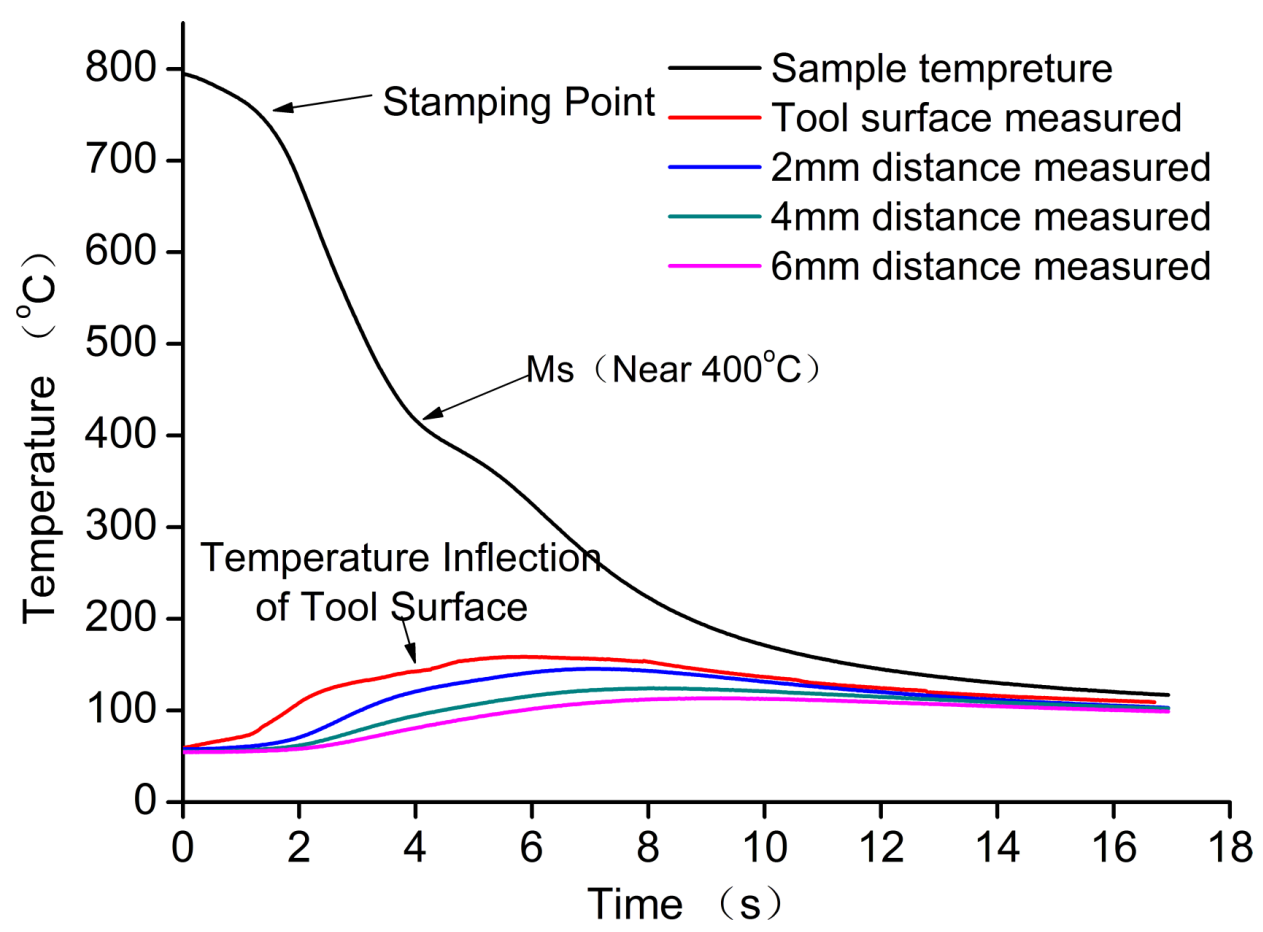

Fig. 4. Measured blank and die temperatures over quenching time

\subsection{Calculation of the IHTC}

According the Newton's law of cooling, the IHTC can be expressed by

$$
h=\frac{q}{\Delta T}
$$

where $q$ is the heat flux density between the blank and the die, and $\Delta T$ the temperature difference of the blank and the die at their interface. Therefore, it is necessary to obtain the temperatures of the blank and the die, as well as the heat flux density, in order to calculate the IHTC.

\subsubsection{Temperature field analysis}

Fig. 5 shows the simulated temperature distribution. In Fig. 5(a), the contour plot shows the temperature distribution in the specimen after 1.0 second of quenching and the graph represents the surface temperature (P1) and the inside temperature (P2) of the specimen over quenching time; while in Fig. 5(b), the contour plot shows the temperature distribution in the die after 10.0 seconds of quenching and the graph represents the surface temperature of the die along the distance from the 
center. It can be observed that the surface temperature the of the specimen is very close to the inside temperature and the peak difference of $732^{\circ} \mathrm{C}$ versus $758^{\circ} \mathrm{C}$ (percentage error of $3.4 \%$ ) occurs approximately after 1.0 second of quenching; and for the die, the surface temperature is uniformly distributed in the center area within a circle of $10 \mathrm{~mm}$ radius and the inside temperature, although gradually decreasing along the depth, is also uniformly distributed around the center axis at the same depth. The preliminary simulation results confirmed that the experiment can be considered as a one dimensional heat transfer problem, i.e. the heat transfers along the thickness direction only.

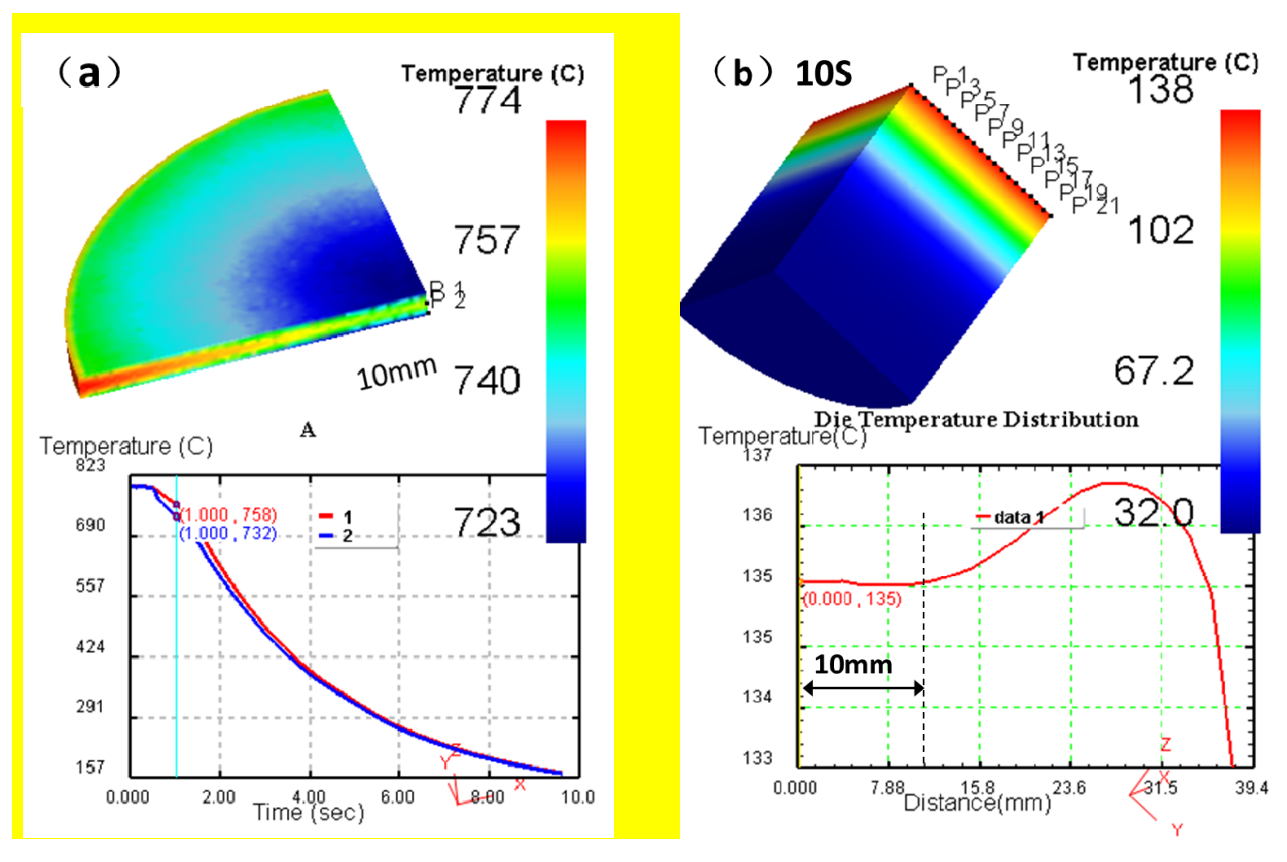

Fig. 5. Simulated temperature distribution in the specimen and the die

The temperature of the blank is close to uniform throughout the thickness in the center area, so the measured blank inside temperature $T_{t, B}^{M E A}$ is considered equal to the calculated blank surface temperature $T_{t, B o}^{C A L}$ at any time, i.e.

$$
T_{t, B}^{M E A} \approx T_{t, B 0}^{C A L}
$$

The die temperature was measured at four locations, namely, on the surface, $2 \mathrm{~mm}, 4 \mathrm{~mm}$ and 6 $\mathrm{mm}$ below the surface. The measured and calculated die temperature are expressed by $T_{t, D i}^{M E A}$ and 
$T_{t, D i}^{C A L}$, respectively, where $i=2,4,6$ denotes the thermocouple location, $t=1,2,,, r$ denotes the time segment over the quenching period.

The temperature is calculated through solving the partial differential equation, Eq. (3), for the one-dimensional unsteady heat conduction problem without internal heat source.

$$
\frac{\partial T}{\partial \tau}=\frac{\lambda}{\rho c} \frac{\partial^{2} T}{\partial x^{2}}
$$

where $T$ is the temperature of the thermal conductor, $\tau$ the time of thermal conduction, $x$ the direction of thermal conduction (the depth of the die in this case), $\rho$ is the density, $c$ the specific heat capacity, and $\lambda$ the heat conductivity coefficient. For the unsteady heat conduction problem, the conditions for deterministic solution consist of two parts: the initial condition providing the temperature distribution of the initial time and the boundary condition providing temperature or heat transfer condition on the boundary of the objects. When the heat flux $q$ at the interface is specified as the boundary condition, it is called the second type of boundary condition, also known as Neumann condition.

\subsubsection{The calculation procedure}

The Beck's nonlinear estimation method is essentially an optimization procedure, which is carried out by adjusting the boundary condition, i.e. the heat flux $q$, over each time segment to minimize the difference between the calculated and measured die temperatures at the three inside locations over the entire quenching period. The overall objective function is expressed by Eq. (4),

$$
\min d_{D}=\min \sum_{t=1}^{r} \sum_{i}\left(T_{t, D i}^{C A L}-T_{t, D i}^{M E A}\right)^{2}
$$

where $r$ is the total number of time segments and $i=2,4,6$.

Adjustment to the heat flux $q$ at time $t$ is given by Eq. (5):

$$
\Delta q_{t}=\frac{\sum_{i=t+1}^{r}\left(T_{M E A}-T_{C A L}\right)_{i} \varnothing_{i}}{\sum_{i=t+1}^{r} \varnothing_{i}^{2}}
$$


where $T_{M E A}$ and $T_{C A L}$ are the measured and calculated die temperatures at the three locations $(2 \mathrm{~mm}$, $4 \mathrm{~mm}$ and $6 \mathrm{~mm}$ below die surface) after time $t$, i.e. from $t+1$ to the end, and $\varnothing_{i}$ is the corresponding sensitivity coefficient of the calculated temperature to the heat flux, which is defined as:

$$
\varnothing=\frac{\partial T}{\partial q}=\frac{T_{C A L}(q(1+e))-T_{C A L}(q)}{q e}
$$

where $e$ is a small number such as 1.0E-4.

The function Pdepe in MATLAB is called to solve the Eq. (3) to get the temperature field of the die over time. The iteration procedure Eq. (4) yields the optimized heat flux $q_{t}$ and die surface temperature $T_{t, D_{0}}^{C A L}$ for each time segment. The calculated blank surface temperature $T_{t, B_{0}}^{C A L}$ is also known from Eq. (2). As a result, the corresponding IHTC can be calculated by:

$$
h_{t}=\frac{q_{t}}{T_{t, D 0}^{C A L}-T_{t, B 0}^{C A L}}
$$

\subsubsection{The calculation results}

The measured and calculated die temperatures over quenching time are plotted in Fig. 6. The die surface temperatures were inversely calculated from the measured die temperatures at $2 \mathrm{~mm}, 4 \mathrm{~mm}$ and $6 \mathrm{~mm}$ below the surface together with the Beck's nonlinear estimation method. The calculated die surface temperatures agree well with the temperatures directly measured by the fusion-welded thermocouple on the upper die surface, with an error of less than 5\%. The estimated IHTC and heat flux versus blank temperature were plotted in Fig. 7. It can be seen that both IHTC and heat flux are not constant during the quenching process. They both increase to a peak value at a certain blank temperature and then drop to zero. In the early quenching stage, the blank is much hotter than the die, so more heat flux occurred at the interface. However, the IHTC is small in the early stage because by definition it is reciprocal to the temperature difference between the blank and die. In the late stage when the blank is cooled down, there is less heat flux but the IHTC is much higher. At the onset and 
end of the experiment, no heat transfer occurred and both HITC and heat flux were zero.

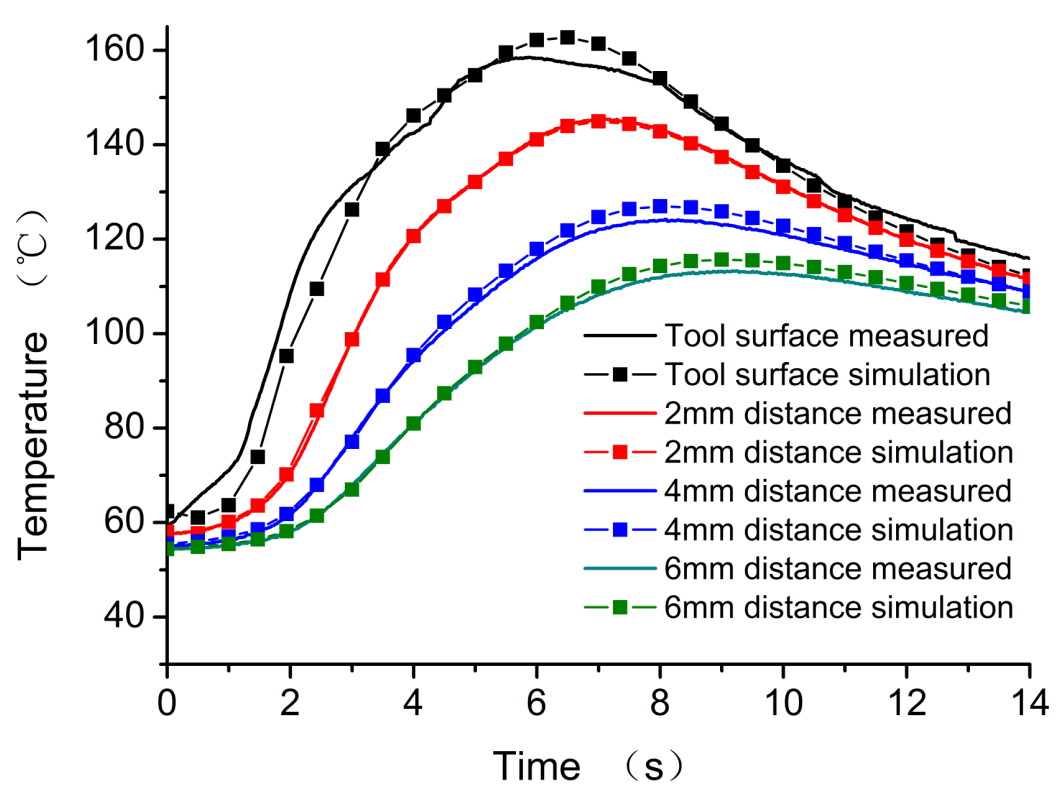

Fig. 6. Measured and calculated die temperatures over quenching time

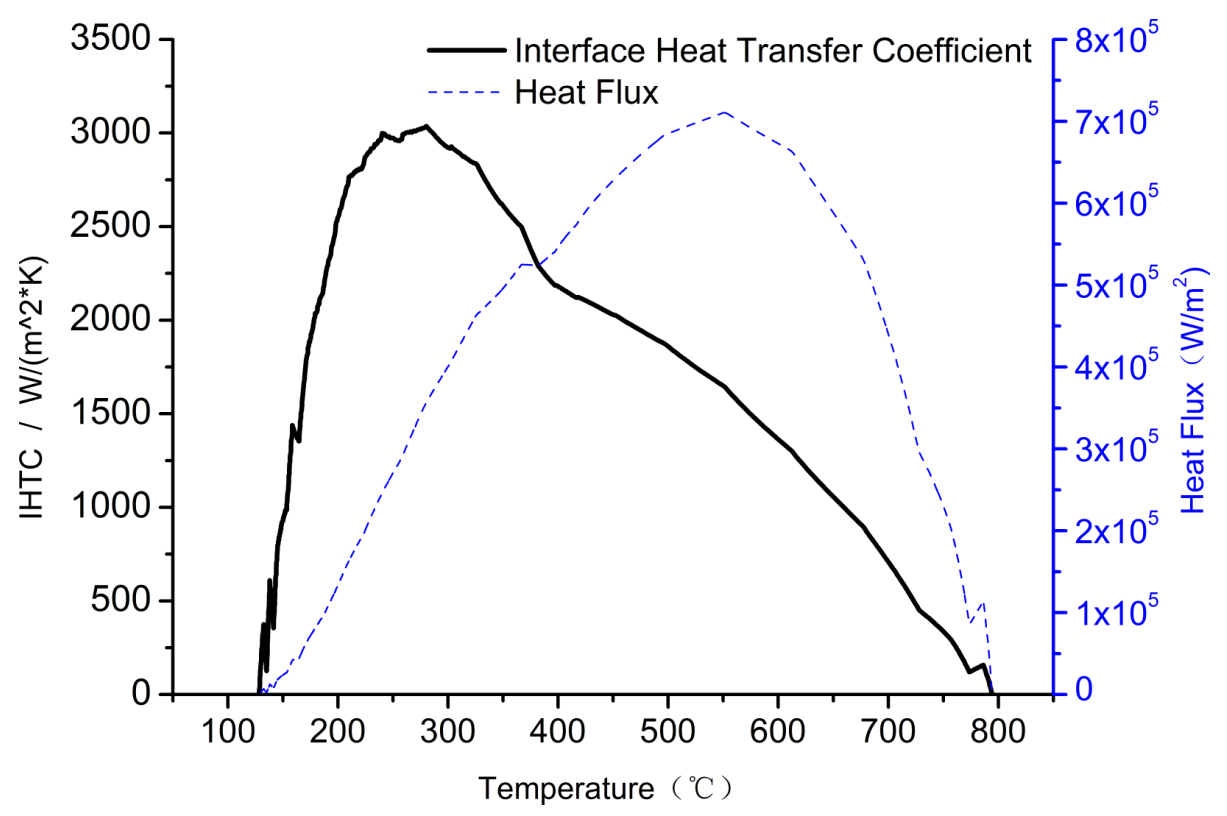

Fig. 7. Plot of IHTC and heat flux versus blank temperature

\section{Factors Influencing the IHTC}

\subsection{Topography at the interface}

The surface of an apparently smooth object is actually rough in microcosmic. As a matter of fact, 
the contact only occurs at some discrete points on the surface of the blank and the die, and the cavities are filled by air or other medium, as shown in Fig. 8. The heat transfer through conduction and convection of the fluid in the cavities is negligible because the cavities are narrow and the heat transfer coefficient of the fluid is small. The radiant heat of the noncontact part is also very small and can be ignored. Therefore, the heat is primarily transferred through the heat conduction between the contacted asperities. The contact pressure and surface roughness etc during hot stamping can change the shape of those asperities and consequently affect the thermal contact resistance. As a result, the IHTC changes over time.

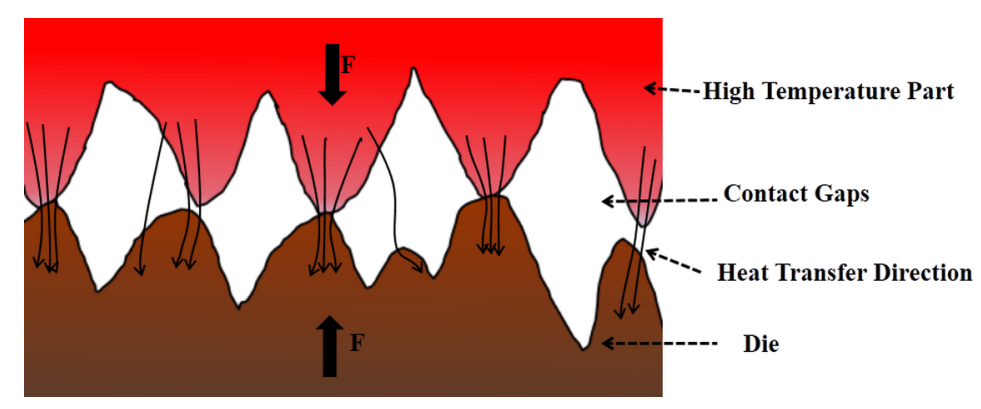

Fig. 8. Micro topography at the interface of blank and die

\subsubsection{Influence of contact pressure on IHTC}

The contact pressure is an important influencing factor on the IHTC. A larger contact force will cause more deformation of the asperities, so the actual contact area will increase and the thermal contact resistance will decrease, resulting in an increase in the heat transfer coefficient.

The surface of a $22 \mathrm{MnB} 5$ steel blank under $5 \mathrm{MPa}$ stamping pressure was scanned by a laser confocal microscope (LEXT OLS4000). Fig 9 shows the surface topography of the blank before and after stamping. The top portion of the cone-shape asperities underwent plastic deformation and became relatively flat. The surface roughness changed from $1.032 \mu \mathrm{m}$ to $0.986 \mu \mathrm{m}$. The stamped blank became smoother than the as-received.

In the experiment, the applied force by the hydraulic press was adjusted to get $0.006 \mathrm{Mpa}, 0.04$ 
Mpa, 1.0 Mpa, 5.0 Mpa, 15 Mpa and 25 Mpa contact pressure between the blank and die, and the blank and die temperatures were measured and recorded for each loading condition. The cooling curves of the blank quenched by \#45-tool-steel die are plotted in Fig. 10. The plots show that a higher contact pressure helped speed up the blank cooling, especially in the pressure range from $0.006 \mathrm{Mpa}$ to 5.0 Mpa. At much higher contact pressures, e.g. from $15 \mathrm{Mpa}$ to $25 \mathrm{Mpa}$, the effect on the cooling rate was not that severe.

The curves of interfacial heat transfer coefficient versus blank temperature are plotted in Fig. 11. It can be seen that the contact pressure has a significant effect on the IHTC, even at much higher pressure like $15 \mathrm{Mpa}$ and $25 \mathrm{Mpa}$. The general trend for the IHTC curves is that they all increase to a peak value at a certain blank temperature and then drop. In the beginning of contact, the temperature difference between the blank and die was large, so was the thermal kinetic force, resulting in rapid IHTC increase. In the later stage when the martensite transformation was complete and the blank temperature approached the die surface temperature, the thermal kinetics became weaker and the IHTC started to decrease. In order to quantify the relationship between the IHTC and contact pressure, an equivalent IHTC is calculated for each contact pressure. Approximately, a power-function relationship exists between the equivalent IHTC and the contact pressure. The best curve fitting in Fig. 12 yields the following function:

$$
I H T C_{\text {eq }}=1829.6 P^{0.2667}
$$

where $P$ is the contact pressure. 

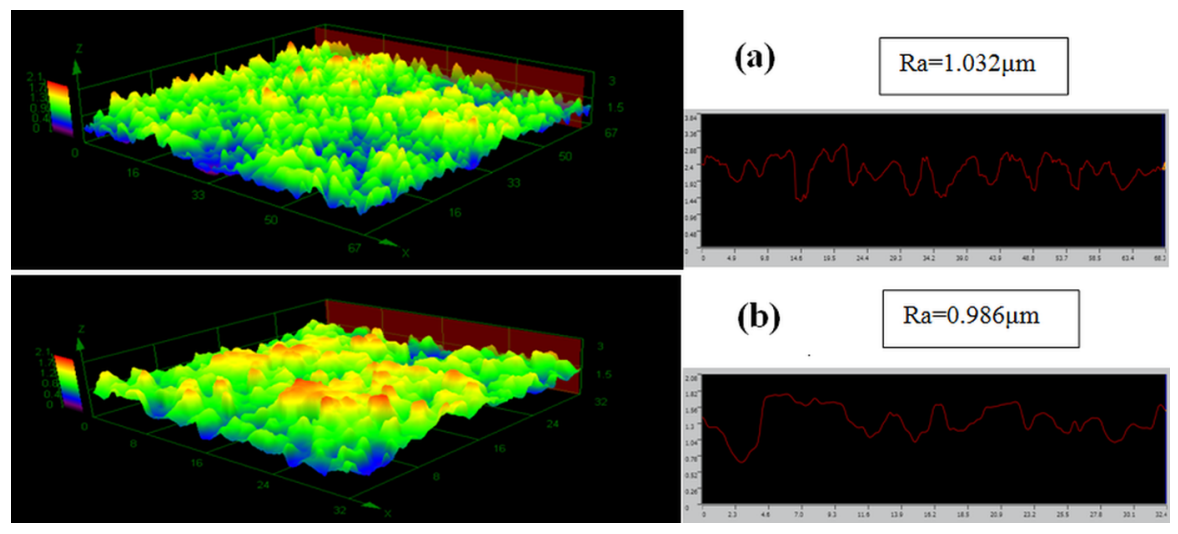

Fig. 9. Surface topography of 22MnB5 blank under 5MPa contact pressure: (a) Magnified by 4000 times before stamping; (b) Magnified by 8000 times after stamping

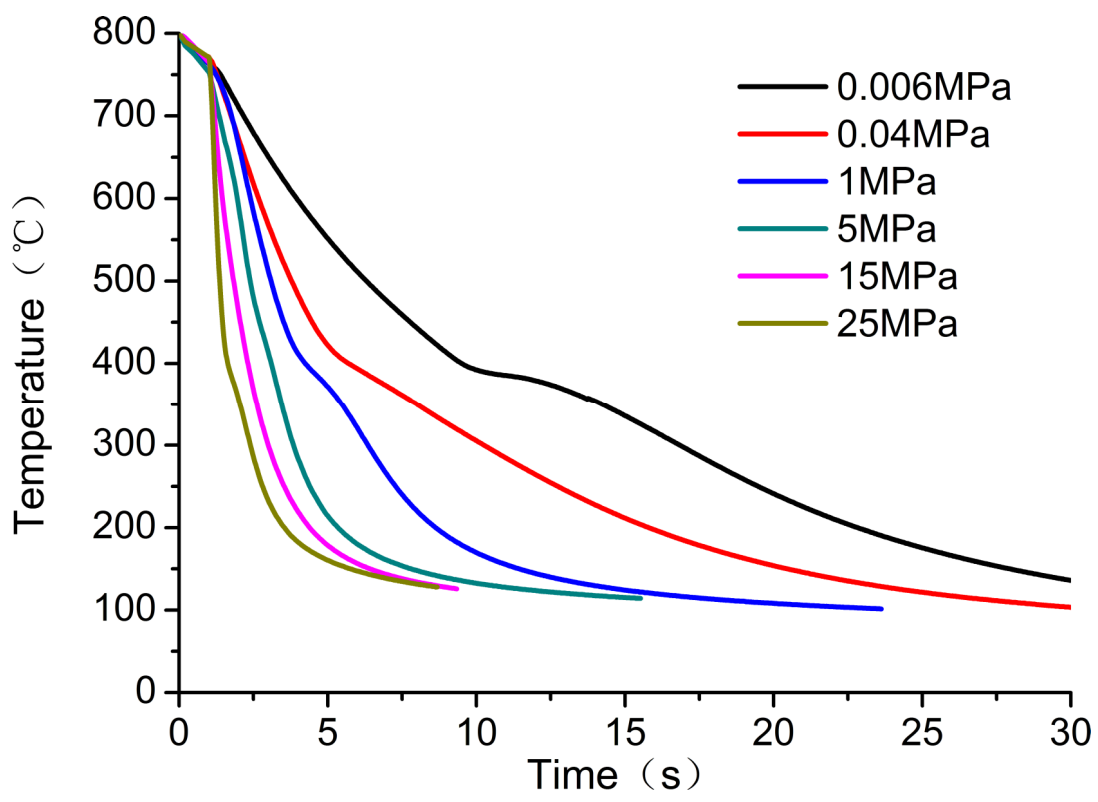

Fig. 10. Cooling curve of the blank under different contact pressures 


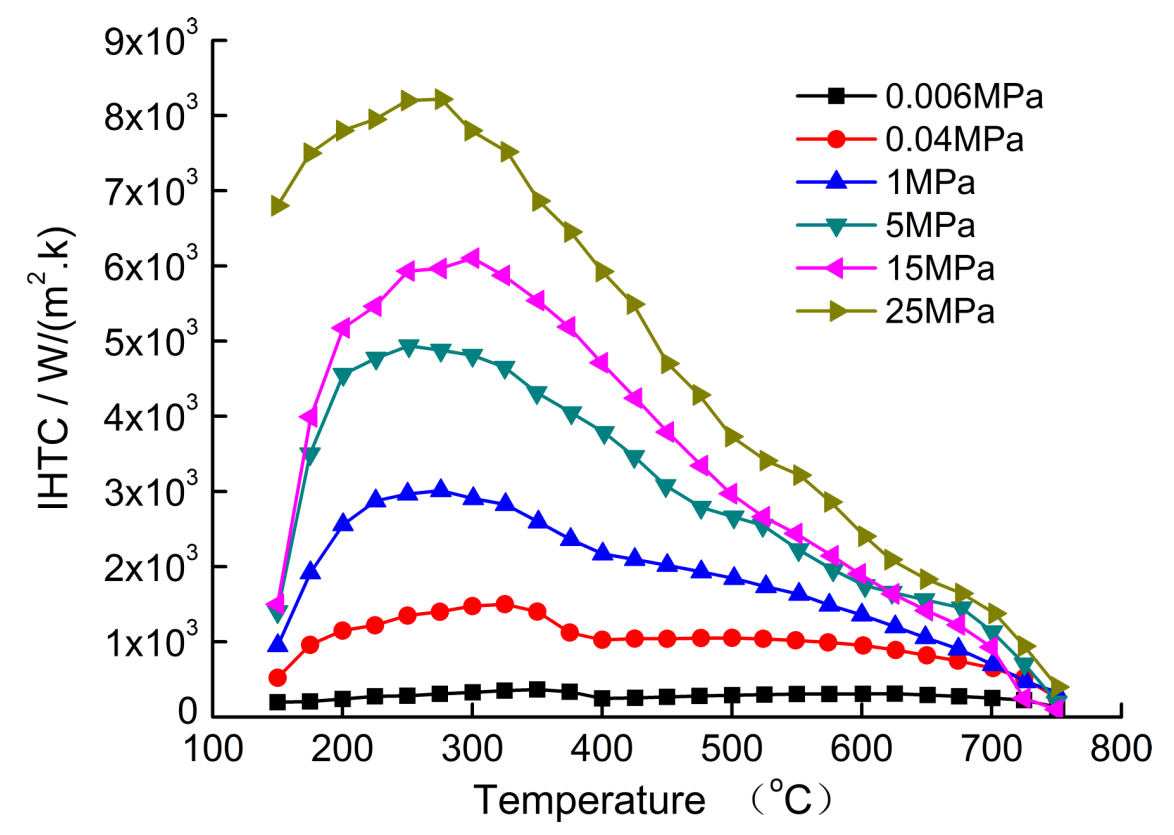

Fig. 11. IHTC versus blank temperature under different contact pressures

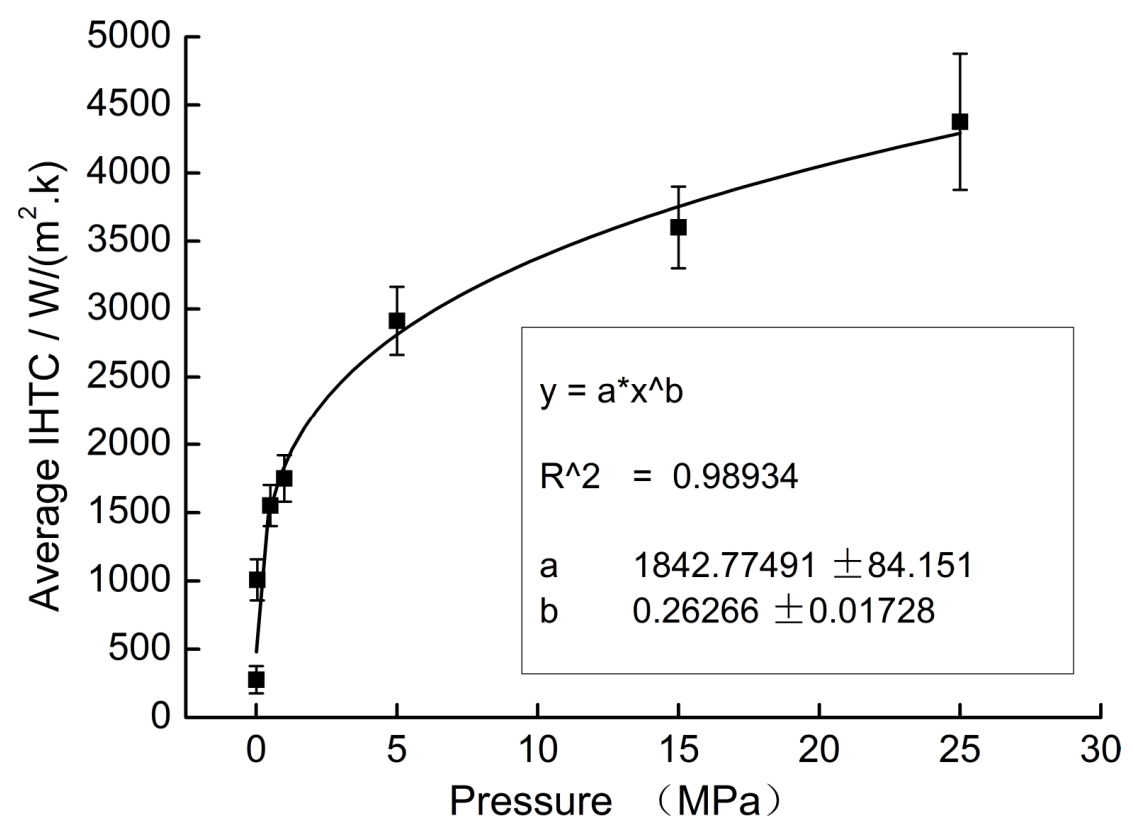

Fig. 12. Curve fitting for the equivalent IHTC versus contact pressure

\subsubsection{Influence of surface roughness on IHTC}

The surface roughness value $R a$ is typically used to characterize how smooth an object's surface is. In order to study the effect of the surface roughness on the IHTC, a set of 22MnB5 steel blanks 
were polished with \#80,\#180,\#240 and \#600 sandpapers to get different surface roughness. The $R a$ values of the as-received and polished blanks are presented in Table 1. No additional polishing was done to the \#45-tool-steel die, so the die surface roughness $R a=0.483$ remains the same throughout the experiment. To visually see the topography difference, the blanks polished with \#180 and \#600 sandpapers after stamping and quenching were laser scanned and the 4000 times magnified surface asperities were presented in Fig. 13.

\section{Table 1}

Surface roughness of the as-received and polished 22MnB5 blanks

\begin{tabular}{|c|c|c|c|c|c|}
\hline Ra (um) & $\begin{array}{c}\text { As-received } \\
\text { blank }\end{array}$ & $\begin{array}{c}\text { \#80 Sandpaper } \\
\text { polished blank }\end{array}$ & $\begin{array}{c}\text { \#180 Sandpaper } \\
\text { polished blank }\end{array}$ & $\begin{array}{c}\text { \#240 Sandpaper } \\
\text { polished blank }\end{array}$ & $\begin{array}{c}\text { \#600 Sandpaper } \\
\text { polished blank }\end{array}$ \\
\hline $\begin{array}{c}\text { Surface } \\
\text { Roughness }\end{array}$ & 1.032 & 3.542 & 1.454 & 0.865 & 0.697 \\
\hline
\end{tabular}
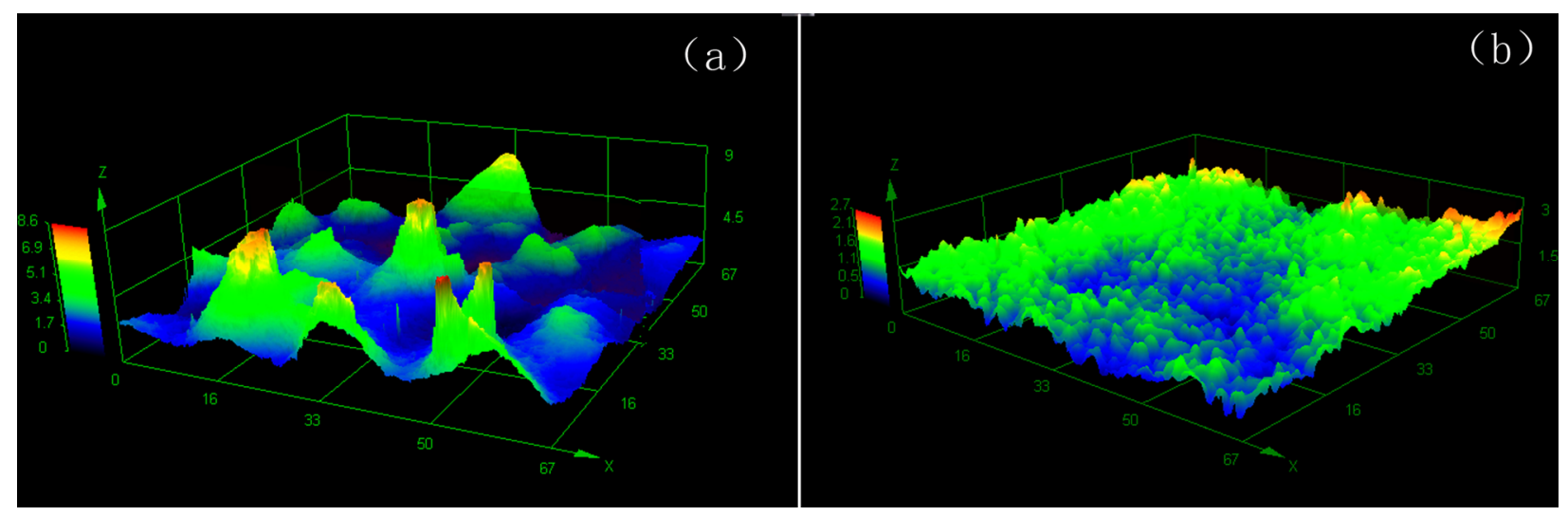

Fig. 13. Surface topography of the blank polished with (a) \#180 sandpaper and (b) \#600 sandpaper

The polished 22MnB5 blanks were heated and then quenched by the \#45-tool-steel die under contact pressure of 1.0 Mpa and 15 Mpa, respectively. The IHTCs were obtained by using the Beck's nonlinear reverse estimation method and an equivalent IHTC was calculated for each scenario. The equivalent IHTC versus surface roughness are plotted in Fig. 14. The plots show that the IHTC 
increases rapidly with decreasing surface roughness when $\mathrm{Ra}>1 \mathrm{um}$, but the pace slows down when $\mathrm{Ra}<1 \mu \mathrm{m}$. The IHTC tends to saturate for smaller surface roughness, especially under high contact pressure. For example, under $15 \mathrm{Mpa}$ contact pressure, the IHTC does not change when the Ra changes from 0.865 um to $0.697 \mathrm{um}$.

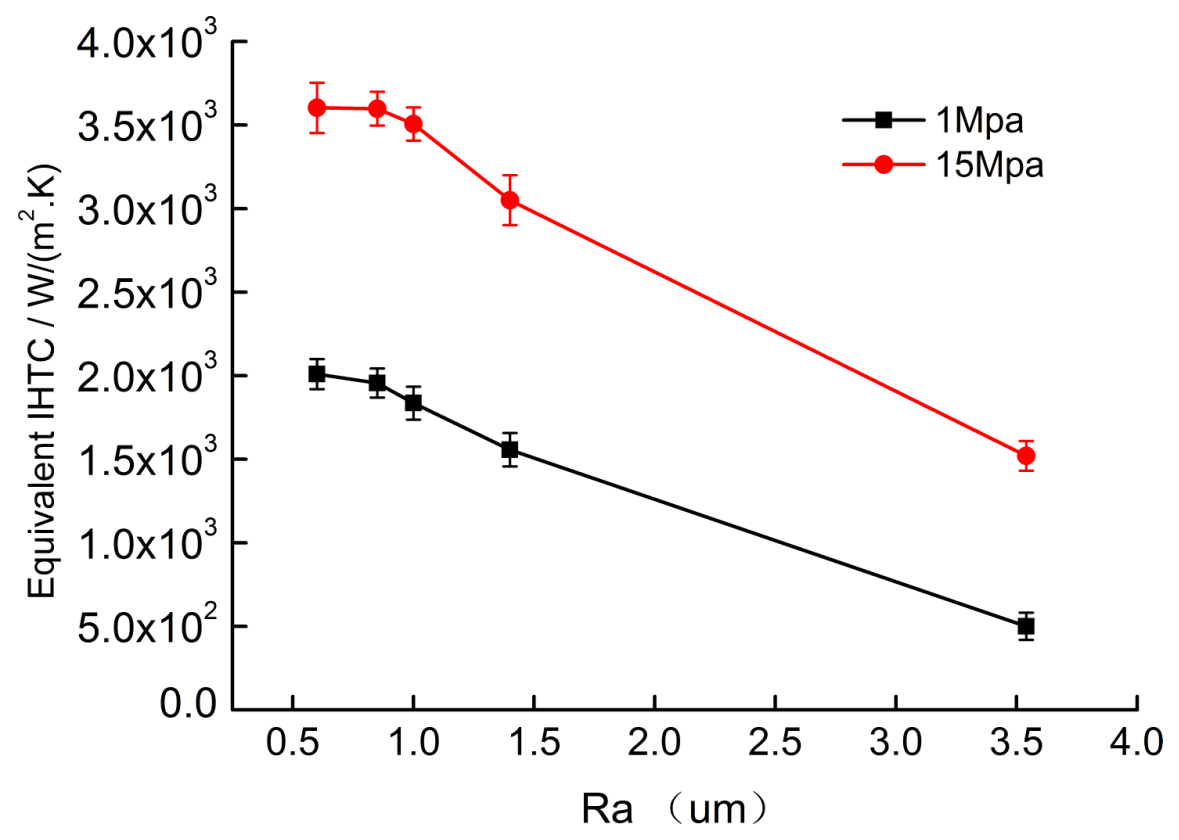

Fig. 14. Relationship between the equivalent IHTC and surface roughness

\subsection{Material thermo-physical properties}

The changes in material thermo-physical properties of the die and blank influence the IHTC. Eq. (3) shows that the temperature field is related to the material density, specific heat capacity, thermal conductivity, etc. Although commonly considered as constants, those thermo-physical properties actually change with temperature. In order to find out the influence of the material thermo-physical properties on the IHTC, experiments of hot stamping 22MnB5 blanks with two types of die, namely, a \#45-tool-steel die and a H13-tool-steel die, were carried out. The influence of phase transformation on IHTC was studied through the experiments of hot stamping 22MnB5 steel blank and AISI-304 stainless steel blank with the same \#45-tool-steel die. Martensite transformation occurs in Boron steel 
22MnB5 during quenching, but not in stainless steel AISI-304. By comparing the IHTC curves, the influence of phase transformation can be figured out.

\subsubsection{Influence of die material on IHTC}

The same type of 22MnB5 blanks were hot stamped and quenched by \#45-tool-steel die and H13-tool-steel die, respectively, and the corresponding blank and die temperatures were measured and recorded. The Beck's nonlinear reverse estimation method was used to get the optimized equivalent IHTC for each die under different contact pressure. The curves of IHTC versus contact pressure for both dies are plotted together in Fig. 15. It can be seen that the IHTC of \#45-tool-steel is much higher than that of H13-tool-steel. For the contact pressure from $0.006 \mathrm{Mpa}$ to $25 \mathrm{Mpa}$, the average \#45-tool-steel IHTC over the average H13-tool-steel IHTC is around 2.21. It is desirable to find out the contribution of each thermo-physical property to difference in IHTC.

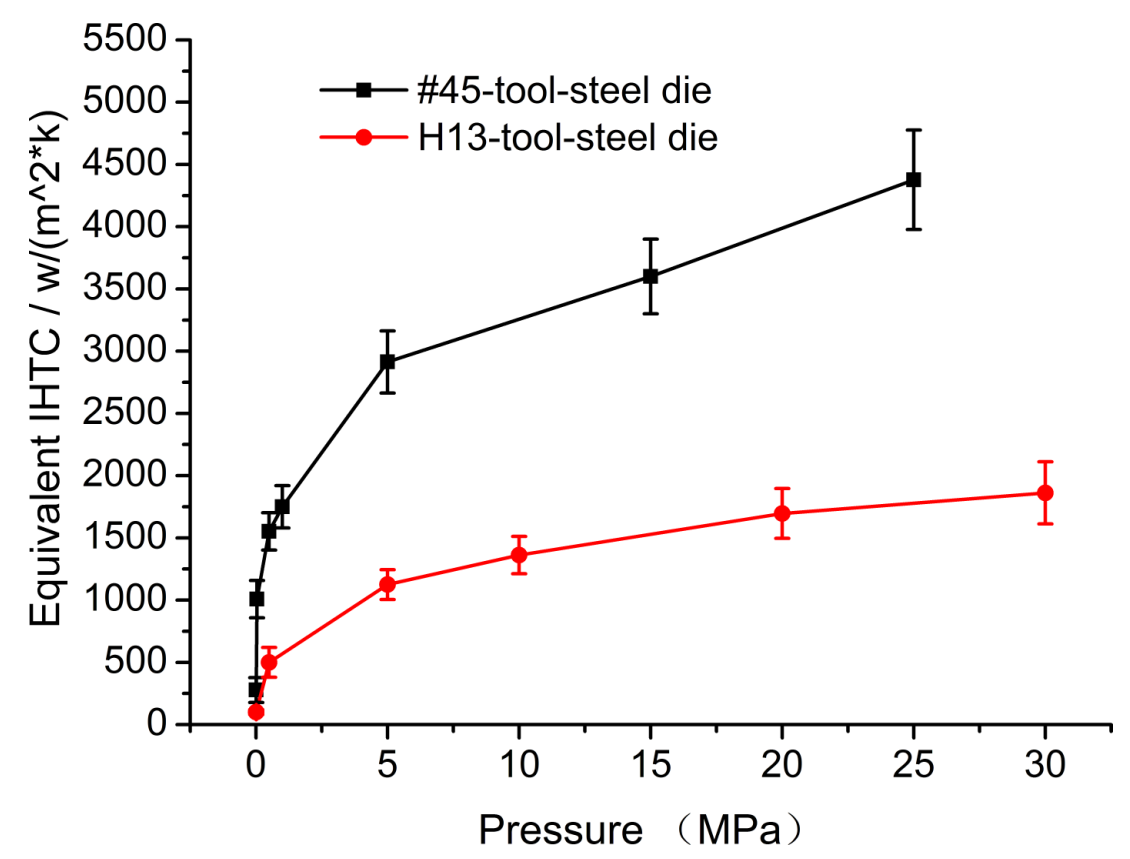

Fig.15. Equivalent IHTC between $22 \mathrm{MnB} 5$ blank and two types of die (\#45-tool-steel die and H13-tool-steel die) versus contact pressure 
As shown in Eq. (3), the thermo-physical properties include three elements: material density $\rho$, thermal conductivity $\lambda$ and specific heat capacity $c$. The combined contribution of these three properties is defined as:

$$
\alpha=\lambda / \rho c
$$

where $\alpha$ is a comprehensive thermo-physical parameter and means the thermal diffusivity used to express the capacity of temperature tending to balance. The higher thermal diffusivity relates to a higher IHTC.

The difference in material density between \#45 tool steel and H13 tool steel is quite small and neglected in this study. The thermal conductivity, specific heat capacity and the thermal diffusivity of these two materials are presented in Table 2 . Since the die temperature is typically below $300^{\circ} \mathrm{C}$ in hot stamping, the difference in thermal properties between these two materials above $300^{\circ} \mathrm{C}$ do not need to be analyzed. For die temperature from $100^{\circ} \mathrm{C}$ to $300^{\circ} \mathrm{C}$, the average thermal conductivity of \#45 tool steel is 1.61 times the thermal conductivity of H13 tool steel, the specific heat capacity is 1.33 times, and the thermal diffusivity is 1.21 times. One interesting finding is that both the ratio of thermal conductivity and the ratio of specific heat capacity of these two steels vary notably for die temperature from $100^{\circ} \mathrm{C}$ to $300^{\circ} \mathrm{C}$, however the ratio of thermal diffusivity is almost constant within this die temperature range. This analysis shows that both thermal conductivity and specific heat capacity influence the IHTC and probably the thermal conductivity contributes more to the difference in IHTC than the specific heat capacity does (because of the different ratio 1.61 versus 1.33). 
Table 2

Thermo-physical properties of \#45-tool-steel and H13-tool-steel

\begin{tabular}{|c|c|c|c|c|c|c|c|}
\hline \multicolumn{7}{|c|}{ Thermal Conductivity, $\gamma, \mathrm{w} /(\mathrm{m} \cdot \mathrm{K})$} \\
\hline Steel & $100^{\circ} \mathrm{C}$ & $200^{\circ} \mathrm{C}$ & $300{ }^{\circ} \mathrm{C}$ & $400^{\circ} \mathrm{C}$ & $500^{\circ} \mathrm{C}$ & $600{ }^{\circ} \mathrm{C}$ & $700^{\circ} \mathrm{C}$ \\
\hline$\# 45$ & 50.7 & 48.1 & 45.7 & 41.7 & 38.3 & 33.9 & 30.1 \\
\hline $\mathrm{H} 13$ & 30.3 & 29.9 & 29.5 & 29.2 & 28.7 & 28.3 & 28.0 \\
\hline Ratio & 1.67 & 1.61 & 1.55 & 1.43 & 1.33 & 1.20 & 1.08 \\
\hline \multicolumn{7}{|c|}{ Specific Heat Capacity, c, J/ $(\mathrm{kg} \cdot \mathrm{K})$} \\
\hline Steel & $100^{\circ} \mathrm{C}$ & $200^{\circ} \mathrm{C}$ & $300^{\circ} \mathrm{C}$ & $400^{\circ} \mathrm{C}$ & $500^{\circ} \mathrm{C}$ & $600^{\circ} \mathrm{C}$ & $700^{\circ} \mathrm{C}$ \\
\hline$\# 45$ & 381.0 & 404.0 & 412.5 & 459.8 & 509.1 & 555.1 & 604.3 \\
\hline H13 & 278.1 & 301.3 & 320.5 & 372.4 & 432.0 & 529.5 & 600.8 \\
\hline Ratio & 1.37 & 1.34 & 1.29 & 1.23 & 1.18 & 1.05 & 1.01 \\
\hline \multicolumn{7}{|c|}{ Thermal diffusivity, $\alpha, \mathrm{m}^{\wedge} 2 / \mathrm{s}$} \\
\hline Steel & $100{ }^{\circ} \mathrm{C}$ & $200{ }^{\circ} \mathrm{C}$ & $300^{\circ} \mathrm{C}$ & $400{ }^{\circ} \mathrm{C}$ & $500{ }^{\circ} \mathrm{C}$ & $600{ }^{\circ} \mathrm{C}$ & $700{ }^{\circ} \mathrm{C}$ \\
\hline$\# 45$ & $1.70 \mathrm{E}-05$ & $1.52 \mathrm{E}-05$ & $1.41 \mathrm{E}-05$ & $1.16 \mathrm{E}-05$ & $9.58 \mathrm{E}-06$ & $7.78 \mathrm{E}-06$ & $6.35 \mathrm{E}-06$ \\
\hline H13 & $1.39 \mathrm{E}-05$ & $1.26 \mathrm{E}-05$ & $1.17 \mathrm{E}-05$ & $9.99 \mathrm{E}-06$ & $8.46 \mathrm{E}-06$ & $6.81 \mathrm{E}-06$ & $5.94 \mathrm{E}-06$ \\
\hline Ratio & 1.22 & 1.21 & 1.21 & 1.16 & 1.13 & 1.14 & 1.07 \\
\hline
\end{tabular}

\subsubsection{Influence of phase transformation on IHTC}

The metallurgical phase transforms from austenite to martensite when the $22 \mathrm{MnB} 5$ boron steel is quenched. The phase transformation leads to microstructure change. As a result, the material thermo-physical properties change as well. Unlike the 22MnB5 boron steel, the AISI-304 austenite stainless steel does not experience phase transformation when quenched. In our experiments, both 22MnB5 blank and AISI-304 blank were hot stamped and quenched by the same die (\#45-tool-steel die). By comparing the cooling curves and the IHTC of these two steels, the effect of phase transformation on IHTC can be found out.

The cooling curves of 22MnB5 boron steel under 0.006 Mpa and 0.04 Mpa pressure and the curves of AISI-304 stainless steel under 0.006 Mpa and 0.2 Mpa pressure are potted in Fig. 16. It can be seen that the cooling curve of $22 \mathrm{MnB} 5$ boron steel has a turning point at near $400^{\circ} \mathrm{C}$ because of the released latent heat during martensite phase transformation. [Sjostrom (1982) studied the latent 
heat and stresses induced by quenching.] On the contrary, the cooling curve of AISI-304 stainless steel is smooth throughout the quenching process without a turning point.

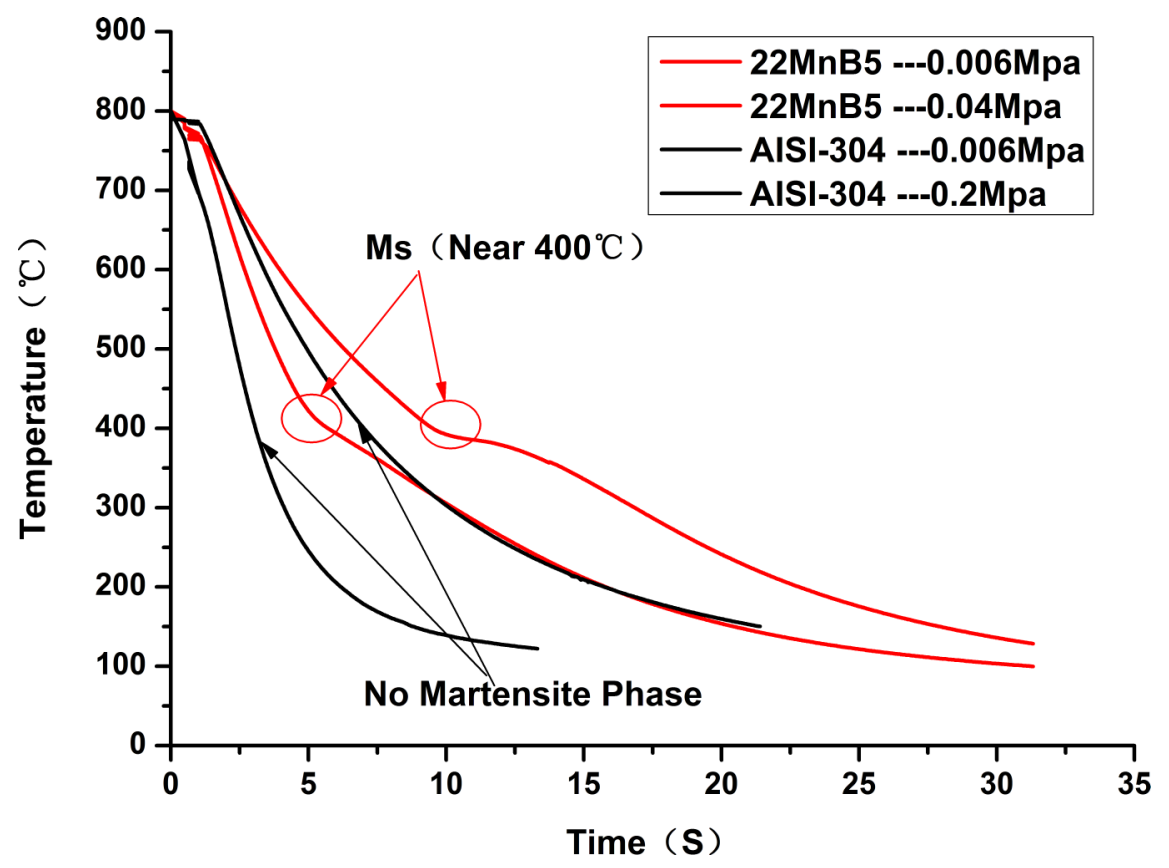

Fig.16. Cooling curves of 22MnB5 boron steel and AISI-304 stainless steel

The estimated IHTC curves for both steels are also plotted together in Fig. 17 for comparison.

The IHTC curves for 22MnB5 boron steel under different contact pressure (0.006 Mpa, $0.04 \mathrm{Mpa}$ and $0.5 \mathrm{Mpa}$ ) all consistently turn at the Ms point (near $400^{\circ} \mathrm{C}$ ), increase rapidly afterwards, and reach the peak value during the phase transformation process. There are no turning points on the IHTC curves for AISI-304 stainless steel because no phase transformation occurs. 


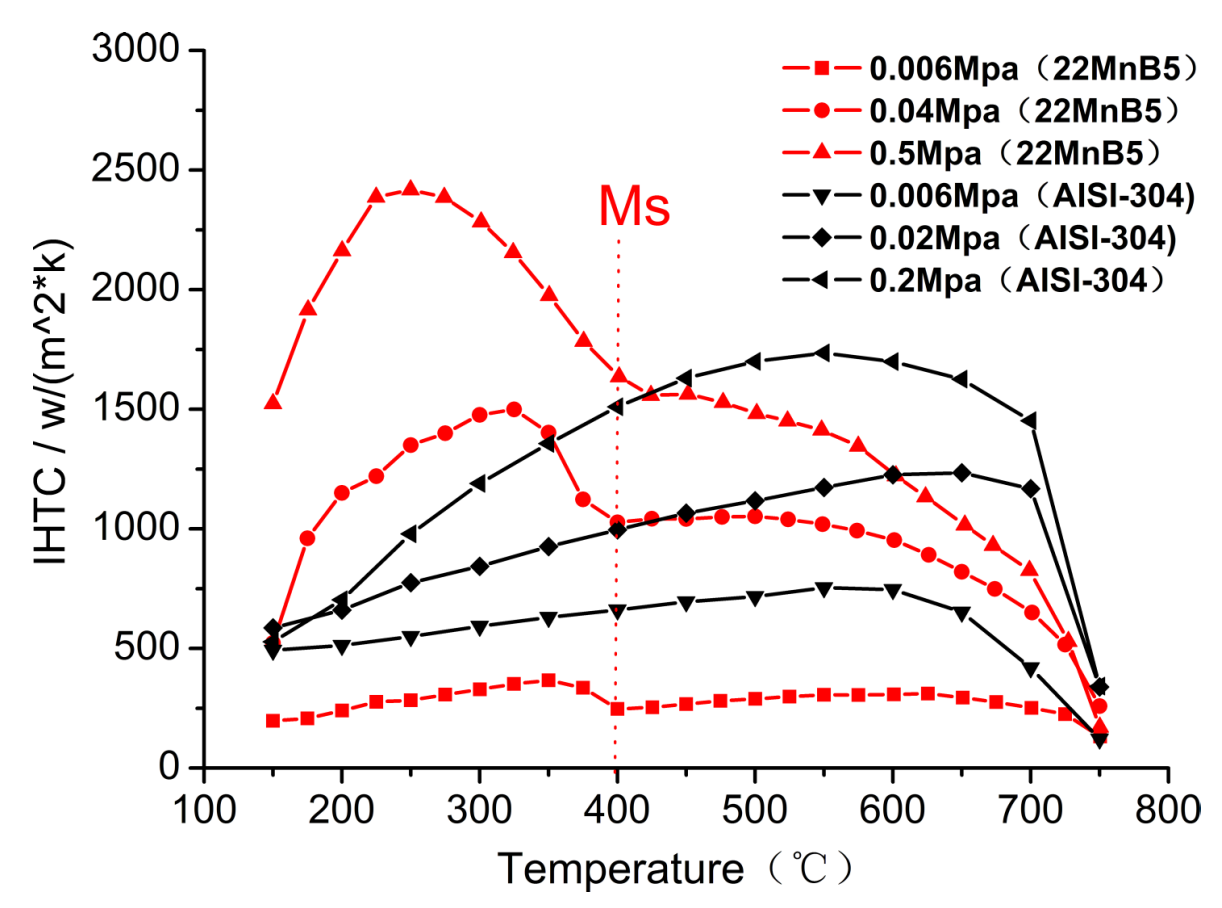

Fig.17. IHTC curves of 22MnB5 boron steel and AISI-304 stainless steel

To quantify the influence of martensite transformation on IHTC, the IHTC gain ( $\triangle \mathrm{IHTC})$ is defined as the difference between the peak IHTC and the IHTC at Ms point, as shown in Fig. 18. Taking into account the effect of contact pressure on IHTC, it is reasonable to use the relative IHTC gain, which is defined as $\triangle \mathrm{IHTC}$ over $\mathrm{IHTC}_{\mathrm{MAX}}$. Fig. 18 presents the relative IHTC gain induced by the phase transformation for $22 \mathrm{MnB} 5$ boron steel under contact pressure of $0.006 \mathrm{Mpa}, 0.04 \mathrm{Mpa}, 0.5$ Mpa, 1.0 Mpa, 5.0 Mpa, 15 Mpa and 25 Mpa. The percentage IHTC gain is about 30\% with 5\% variation for different contact pressure. 


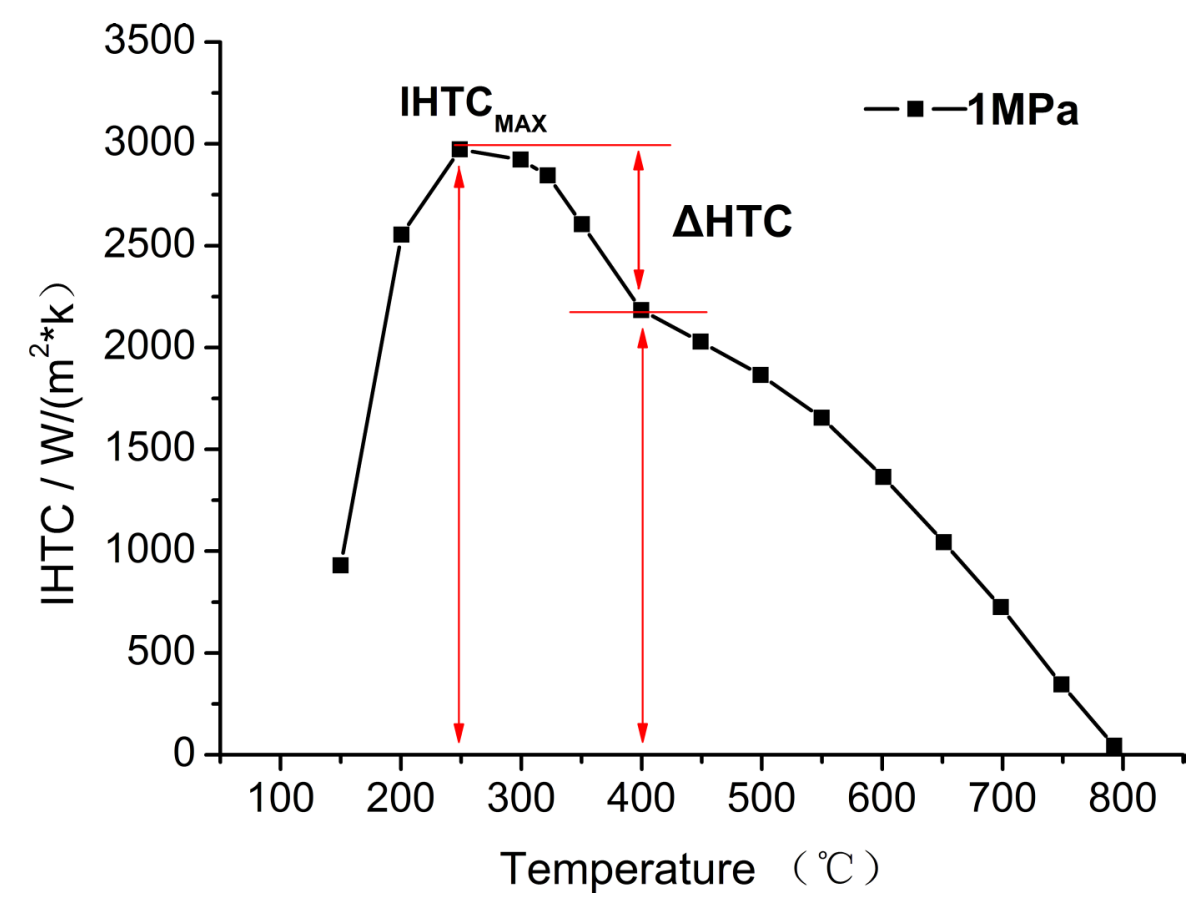

Fig.18. Definition of IHTC gain $(\triangle \mathrm{IHTC})$ induced by martensite transformation

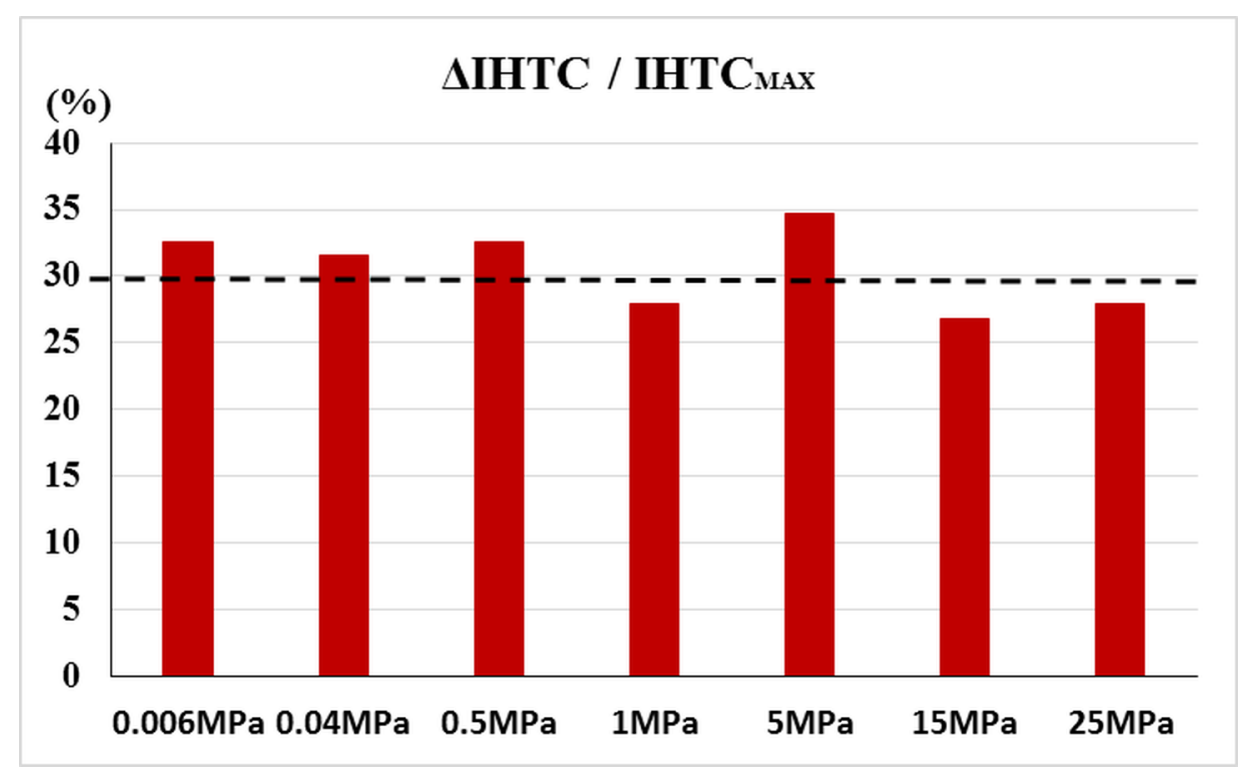

Fig.19. IHTC gain $(\triangle \mathrm{IHTC})$ for different contact pressure

To influence of phase transformation on the IHTC gain can be explained by the changes in thermo-physical properties associated with the transformation from austenite to martensite. For $22 \mathrm{MnB} 5$ steel, the specific heat capacity in martensite phase is less than in austenite phase, but it 
changes gradually over temperature and does not suddenly drop at the Ms point. Therefore, the change in specific heat capacity does not help explain the turning point on the IHTC curve.

Martensite transformation causes volume expansion by approximately $2 \%$, resulting in a small change in density, which is too small to impact the IHTC significantly. On the contrary, the thermal conductivity of martensite is significantly larger than that of austenite, especially at lower temperature. During the phase transformation process, the material microstructure consists of both austenite and martensite. The thermal conductivity of the mixed microstructure can be derived from the martensite transformation rate and the martensite extent can be calculated by the Koistinen-Marburger's (1959) law,

$$
\xi(\mathrm{T})=1-\exp \left[-\alpha\left(\mathrm{M}_{\mathrm{s}}-\mathrm{T}\right)\right]
$$

where $\zeta$ is the martensite volume fraction, $M_{S}$ the martensite transformation temperature, $T$ the specimen temperature, and $\alpha$ the phase transformation kinetic factor. The $M_{s}$ and $\alpha$ are related the chemical compositions of the material and $M_{s}$ is also related to the contact pressure. In this study, the $M_{s}$ for $22 \mathrm{MnB} 5$ is set as $400^{\circ} \mathrm{C}$. Akerstrom and Oldenburg (2006) pointed out the appropriate value for $\alpha$ is 0.011 .

The thermal conductivity of austenite and martensite versus temperature are plotted in Fig. 20. In the phase transformation region, i.e. between $400^{\circ} \mathrm{C}$ and $240^{\circ} \mathrm{C}$, the conductivity of the mixed austenite-martensite phase is the weighted average of the conductivities of each single phase. The weight for the martensite is calculated by Eq. (10). The transition of thermal conductivity is also illustrated in Fig. 20. Besides the thermal conductivity, the heat flux density turns near the $M_{s}$ point, especially at lower contact pressure, as show in Fig. 21. The heat flux density values were best estimated using the Beck's reverse method.

Both the change in thermal conductivity and the release of latent heat contribute to the turning of the cooling curve (Fig. 16) and the IHTC curve (Fig. 17) near the $M_{s}$ point. The blank temperature drop slows down near the $M_{s}$ point is primarily because of the released latent heat induced by the 
martensite transformation. In the meanwhile, the increased thermal conductivity helps transfer more heat from the blank to the die. The combination of thermal conductivity increasing and latent heat releasing results in a sharp increase of the IHTC near the $M_{s}$ point.

Additionally, the transformation induced plasticity, volume expansion (Naderi et al. 2008) and surface relief (Liu et al. 2011) during the martensite transformation lead to contact pressure increasing and actual contact area enlarging at the interface. This helps reduce the thermal contact resistance and increase the IHTC as a consequence.

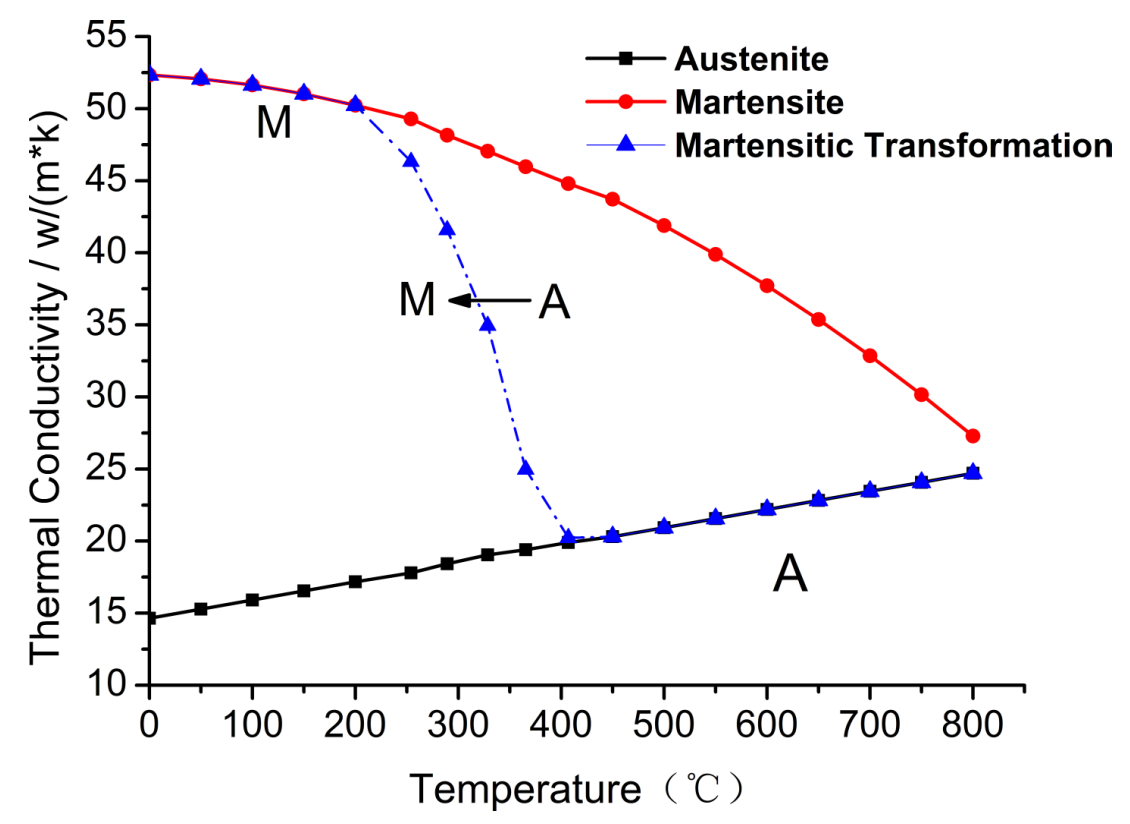

Fig.20. Illustration of change in thermal conductivity during phase transformation 


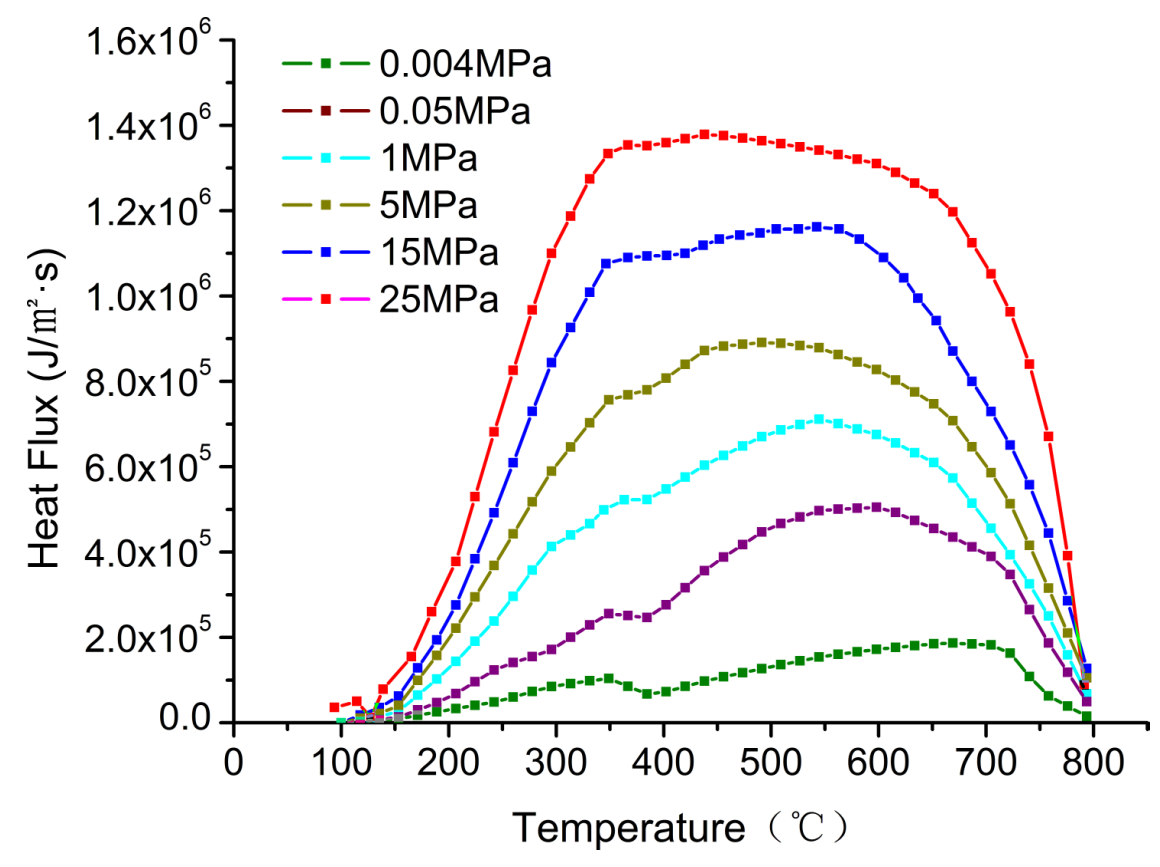

Fig.21. Estimated heat flux density versus blank temperature at different contact pressure

\subsection{Influence of anti-oxidation coating on IHTC}

When the heated 22MnB5 steel blank is subsequently hot stamped and quenched, the blank surface will oxidize. Hu et al. (2011) studied the thermal conductivity of the oxide scale and concluded that the oxide scale increases the thermal contact resistance and reduces the heat transfer coefficient. The oxide scale also generates additional friction between die and blank, which accelerates die wear and reduces die life.

The widespread protection for $22 \mathrm{MnB} 5$ blank is an Al-Si based plating layer that prevents scale formation during hot stamping operation and the chemical behaviors of the coating layer has been studied by Borsetto et al. (2009). Another method for preventing oxidation is coating the blank with preventive oil as described by Mori and Ito (2009). The influence of the Al-Si coating on heat transfer between blank and die has been studied by some scholars, but no literature is available for the influence of the preventive oil.

In this study, the influence of the anti-oxidation oil coating on the IHTC was investigated. The 
oil consists of oil-based fatty acid soap, boric acid and phosphate solid lubricants, metallic soap, sequestering agent. Better oxidation prevention requires a thicker coating layer. The coating thickness was increased from $42 \mu \mathrm{m}$ to $117 \mu \mathrm{m}, 133 \mu \mathrm{m}$ and $207 \mu \mathrm{m}$ by repeating the application of sponge rubber and drying. The IHTC between the oil-coated 22MnB5 blanks and the \#45-tool-steel die under 25 Mpa pressure were estimated using the Beck's method and plotted in Fig. 22. Comparison of Fig. 22 and Fig. 11 (IHTC of bare 22MnB5 blanks) reveals that the anti-oxidation oil coating reduces the IHTC significantly. For example, the peak IHTC of the blank coated with $42-\mu \mathrm{m}$ thick oil is about $2500 \mathrm{~W} /\left(\mathrm{m}^{2} \mathrm{~K}\right)$, much lower than that of the bare blank, which is $8100 \mathrm{~W} /\left(\mathrm{m}^{2} \mathrm{~K}\right)$.

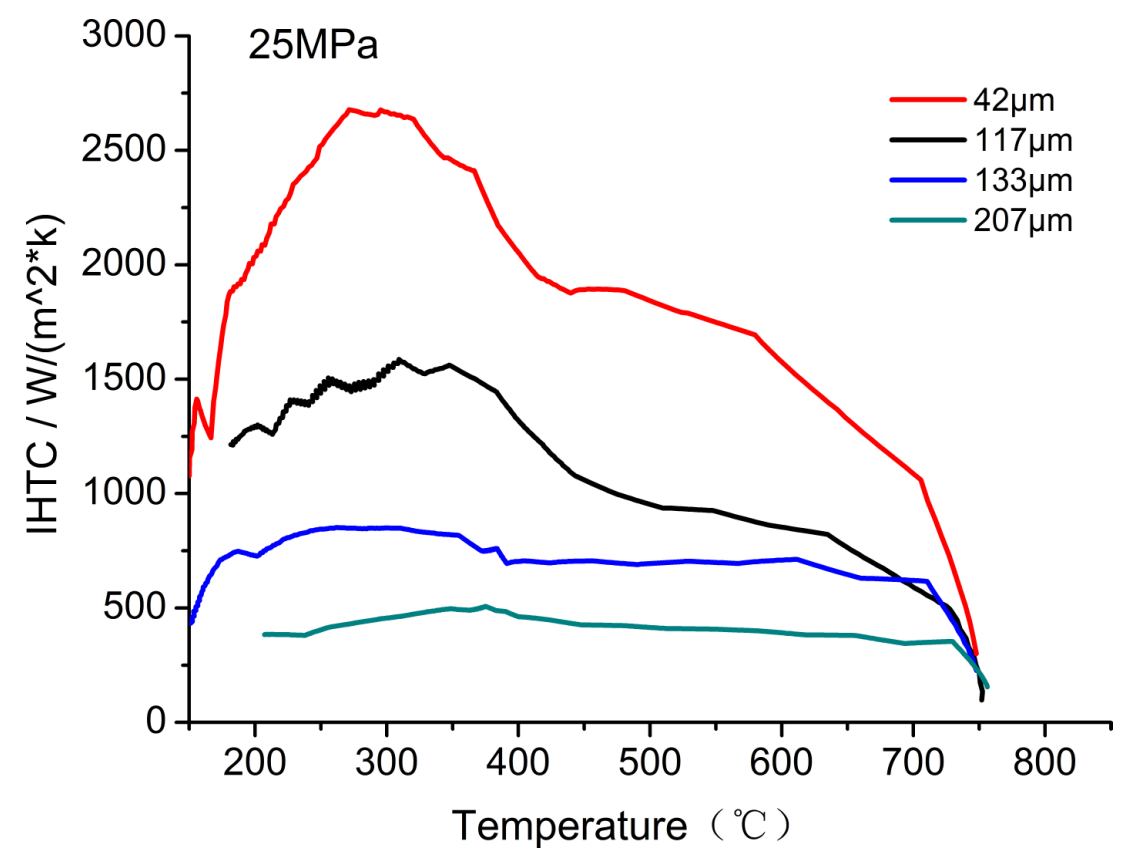

Fig.22. IHTC of oil-coated blanks under $25 \mathrm{Mpa}$ contact pressure (coating thickness is $42 \mu \mathrm{m}$, $117 \mu \mathrm{m}, 133 \mu \mathrm{m}$ and $207 \mu \mathrm{m})$

\section{Conclusions}

In this paper, the influences of the topography at the interface, the materials thermo-physical properties and the anti-oxidation surface coating on the interfacial heat transfer coefficient (IHTC) of $22 \mathrm{MnB} 5$ boron steel blanks were investigated based on an in-house designed hot stamping device 
and the Beck's nonlinear reverse estimation method. The following conclusions were drawn.

(1) The Beck's nonlinear reverse estimation method is a robust and accurate method for identifying the IHTC in hot stamping operations. The error between the estimated and measured die surface temperatures is less than $5 \%$.

(2) Both contact pressure and blank surface roughness impact the topography at the interface. Higher contact pressure causes more deformation of the asperities at the interface, so the actual contacting area enlarges and the thermal contact resistance decreases, resulting in an increase in the IHTC. The IHTC correlates highly with contact pressure by a positive power function. The IHTC increases rapidly with decreasing surface roughness when $\mathrm{Ra}>1.0 \mu \mathrm{m}$, but when $\mathrm{Ra}<0.9 \mu \mathrm{m}$, the pace slows down and the IHTC tends to saturate, especially under high contact pressure.

(3) The IHTC of \#45-tool-steel is about 2.1 times that of H13-tool-steel. Among the material thermo-physical properties, the thermal conductivity and specific heat capacity are the primary influencing factors on the IHTC.

(4) The martensitic transformation yields a positive gain on IHTC by approximately $30 \%$. The combination of phase transformation induced thermal conductivity increasing and latent heat releasing results in a sharp increase of the IHTC near the $M_{s}$ point.

(5) Although the oxidation preventive oil coating can reduce oxidation of the blank, it reduces the IHTC significantly. Under the same contact pressure, the IHTC of the 22MnB5 blank coated with $42-\mu \mathrm{m}$ thick oil is about $1 / 3$ that of the bare blank. The IHTC decreases more with a thicker coating.

\section{Acknowledgements}

This research is financially supported by China Natural Science Foundation (11472072), NSF of Liaoning Province (2014028001), China Central Universities Fundamental Research Funds (DUT12RC(3)95, DUT12RC(3)100). 


\section{References}

Abdulhay, B., Bourouga B., Dessain, C., 2012. Thermal contact resistance estimation: influence of the pressure contact and the coating layer during a hot forming process. International Journal of Material Forming 5 (3), 1-15.

Akerstrom, P., Oldenburg, M., 2006. Austenite decomposition during press hardening of a boron steel - computer simulation and test. Journal of Materials Processing Technology 174 (2006), 399-406.

Bai, Q., Lin, J., Zhan, L., Dean, T.A., Balint, D.S., Zhang, Z., 2012. An efficient closed-form method for determining interfacial heat transfer coefficient in metal forming. International Journal of Machine Tools and Manufacture 56, 102-110.

Beck, J., Bleckwell, B., Clair, C., 1985. Inverse heat conduction. John Wiley \& Sons Inc.

Blaise, A., Bourouga, B., Abdulhay, B., Dessain, C., 2013. Thermal contact resistance estimation and metallurgical transformation identification during the hot stamping. Applied Thermal Engineering 61 (2), 141-148.

Borsetto, F., Ghiotti, A., Bruschi, S., 2009. Investigation of the high strength steel Al-Si coating during hot stamping operations. Key Engineering Materials 410-411, 289-296.

Chen, W.C, Samarasekera, I.V., Hawbolt, E.B. 1993. Fundamental phenomena governing heat transfer during rolling. Metallurgical Transactions 24A(6), 1307-1320.

Hu, P., Ying, L., Li, Y., Liao, Z., 2013. Effect of oxide scale on temperature-dependent interfacial heat transfer in hot stamping process. Journal of Materials Processing Technology 213 (9), $1475-1483$.

Ikeuchi, K., Yanagimoto, J., 2011. Valuation method for effects of hot stamping process parameters on product properties using hot forming simulator. Journal of Materials Processing Technology $211(8), 1441-1447$.

Karbasian, H., Tekkaya, A.E., 2010. A review on hot stamping. Journal of Materials Processing Technology 210 (15), 2103-2118. 
Koistinen, D.P., Marburger, R.E., 1959. A general equation prescribing the extent of the austenite-martensite transformation in pure iron-carbone alloys and plain carbon steels. Acta Metallurgica 1959 (7), 59-60.

Liu, H., Jin, X., Dong, H., Shi, J., 2011. Martensitic microstructural transformations from the hot stamping, quenching and partitioning process. Materials Characterization 62 (2), 223-227.

Merklein, M., Lechler, J., Stoehr, T., 2009. Investigation on the thermal behavior of ultra high strength born manganese steels within hot stamping. International Journal of Material Forming 2 (1), 259-262.

Mori, K., Ito, D., 2009. Prevention of oxidation in hot stamping of quenchable steel sheet by oxidation preventive oil. CIRP Annals-Manufacturing Technology 58 (1), 267-270.

Naderi, M., Saeed-Akbari, A., Bleck, W., 2008. The effects of non-isothermal deformation on martensitic transformation in 22MnB5 steel. Materials Science and Engineering: A 487 (1-2), 445-455.

Shojaefard, M.H., Goudarzi, K., 2008. The numerical estimation of thermal contact resistance in contacting surfaces. American Journal of Applied Sciences 5 (11), 1566-1571.

Sjostrom, S., 1982. The calculation of quench stresses in steel. PhD thesis, Linkoping University, Sweden.

Turetta, A., Bruschi, S., Ghiotti, A., 2006. Investigation of 22MnB5 formability in hot stamping operations. Journal of Materials Processing Technology 177 (1-3), 396-400.

Yang, S.M, Tao, W.Q., 2006. Heat Transfer Theory. Beijing: Higher Education Press (in Chinese). 


\section{Table and Figure Captions}

Fig. 1. Schematic illustration of the experiment setup

Fig. 2. Dimensions of the heat transfer device and the thermocouple positions

Fig. 3. Experiment setup showing the specimen and thermocouple wiring

Fig. 4. Measured blank and die temperatures over quenching time

Fig. 5. Simulated temperature distribution in the specimen and the die

Fig. 6. Measured and calculated die temperatures over quenching time

Fig. 7. Plot of IHTC and heat flux versus blank temperature

Fig. 8. Micro topography at the interface of blank and die

Fig. 9. Surface topography of 22MnB5 blank under 5MPa contact pressure: (a) Magnified by 4000 times before stamping; (b) Magnified by 8000 times after stamping

Fig. 10. Cooling curve of the blank under different contact pressures

Fig. 11. IHTC versus blank temperature under different contact pressures

Fig. 12. Curve fitting for the equivalent IHTC versus contact pressure

Fig. 13. Surface topography of the blank polished with (a) \#180 sandpaper and (b) \#600 sandpaper

Fig. 14. Relationship between the equivalent IHTC and surface roughness

Fig.15. Equivalent IHTC between 22MnB5 blank and two types of die (\#45-tool-steel die and H13-tool-steel die) versus contact pressure

Fig.16. Cooling curves of 22MnB5 boron steel and AISI-304 stainless steel

Fig.17. IHTC curves of 22MnB5 boron steel and AISI-304 stainless steel

Fig.18. Definition of IHTC gain $(\triangle \mathrm{IHTC})$ induced by martensite transformation

Fig.19. IHTC gain $(\triangle \mathrm{IHTC})$ for different contact pressure

Fig.20. Illustration of change in thermal conductivity during phase transformation

Fig.21. Estimated heat flux density versus blank temperature at different contact pressure

Fig.22. IHTC of oil-coated blanks under $25 \mathrm{Mpa}$ contact pressure (coating thickness is $42 \mu \mathrm{m}$, 
$117 \mu \mathrm{m}, 133 \mu \mathrm{m}$ and $207 \mu \mathrm{m})$

Table 1 Surface roughness of the as-received and polished 22MnB5 blanks

Table 2 Thermo-physical properties of \#45-tool-steel and H13-tool-steel 